\title{
Dynamics of Methanotrophs during in situ Bioremediation
}

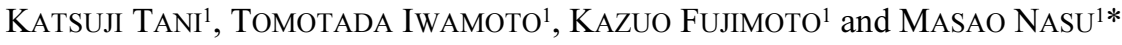 \\ ${ }^{1}$ Environmental Science and Microbiology, Graduate School of Pharmaceutical Sciences, Osaka University, 1-6, \\ Yamada-oka, Suita, Osaka 565-0871, Japan
}

(Received September 2, 2000-Accepted December 25, 2000)

Changes in diversity of type I and type II methanotrophs during a biostimulation field experiment were investigated for 73 days after the start of treatment by denaturing gradient gel electrophoresis (DGGE) analysis of PCR-amplified 16S rDNA fragments. DGGE profiles of the type I and type II methanotrophs yielded simple banding patterns. The type I methanotrophs' profile showed a single intense band at day 10 of biostimulation, and sequence analysis showed 99\% similarity with Methylobacter psychrophilus. The type II methanotrophs' profile showed a single band appeared at day 31, becoming an intense band after day 40 . Sequence analysis of this band pattern showed $99 \%$ similarity with Methylocystis parvus. These results suggest a possible shift of numerically dominant methanotrophs from type I to type II during the field experiment.

Key words: methanotrophs, DGGE, bioremediation

Methanotrophs are widespread in natural habitats, and have attracted the interest of microbiologists due to their potential for use in bioremediation ${ }^{1-5)}$ and their importance in the global methane cycle ${ }^{6}$. Two categories of methanotrophs, type I and type II, have been identified using a polyphasic approach ${ }^{7,8)}$. Type I methanotrophs, which contain bundles of intracytoplasmic membranes and assimilate carbon via the ribulose monophosphate pathway, fall within the gamma-Proteobacteria category9). Type II methanotrophs, which possess intracytoplasmic membranes arranged around the periphery of the cell and assimilate carbon via the serine pathway, fall within the alpha-Proteobacteria category ${ }^{9}$. Among the alpha- and gamma-Proteobacteria, all close relatives of methanotrophs are methane utilizers ${ }^{10)}$, with one exception ${ }^{11)}$. Therefore, phylogenetic placement can be a reliable indicator of methanotrophs.

Since methanotrophs are capable of cometabolic oxidation of trichloroethylene (TCE) $)^{9}$, which is one of the most common environmental contaminants in soil and groundwater, this bacterial group has received attention for possible use in bioremediation of TCE. Understanding the commu-

\footnotetext{
* Corresponding author; E-mail: nasu@phs.osaka-u.ac.jp, Tel: +816-6879-8170, Fax: +81-6-6879-8174
}

nity structure of methanotrophs during bioremediation would facilitate better management of biostimulation with methane injection. However, traditional culture-based approaches are limited for this purpose, because many methanotrophs are difficult to cultivate ${ }^{12,13)}$. Therefore, cultureindependent approaches such as molecular biological techniques must be utilized to examine methanotrophs in the natural environment.

Employing the 16S rRNA gene as a molecular marker, microbiologists have been able to identify the presence of novel, uncultured organisms in nature ${ }^{14)}$. We exploited the restricted phylogeny of methanotrophs to design type I and type II methanotroph-specific $16 \mathrm{~S}$ rDNA primers. Using the primers for PCR-DGGE (Denaturing Gradient Gel Electrophoresis) analysis, changes in the diversity of the methanotrophic bacterial community during a biostimulation field experiment were investigated.

The objectives of this investigation were to better understand the phylogenetic affiliation of the methanotrophs that grew in response to the addition of methane to the on-site biostimulation test site located in Kururi, Kimitsu City, Chiba Prefecture, where the groundwater was contaminated with TCE, and to monitor changes in the diversity of type I and type II methanotrophs during the biostimulation field 
experiment.

\section{Materials and Methods}

\section{Sample site, treatment, and sampling}

The location of the sampling well, injection well, and extraction well at Kururi experimental site in Chiba prefecture are illustrated in Figure 1. The TCE concentration in groundwater at the experimental site was approximately $200 \mu \mathrm{g} / \mathrm{l}$ and the biostimulation was started on September 25 in 1998. The aquifer characteristics in this field have been described by Hanada et al. ${ }^{15}$. Details of bacterial abundance and results of TCE remediation studies were reported by Iwamoto et al. ${ }^{16)}$. Biostimulation was conducted by circulating chemically augmented groundwater between the injection well and extraction well at $1.5 \mathrm{l} / \mathrm{min}$. Injected groundwater was constantly augmented under the following conditions; methane addition to a dissolved methane concentration of $10 \mathrm{mg} / \mathrm{l}$ for $190 \mathrm{~min}$, no addition of chemical substances for $50 \mathrm{~min}$, addition of oxygen (dissolved oxygen concentration of $30 \mathrm{mg} / \mathrm{l})$ and nutrient salts $\left(\mathrm{KNO}_{3}\right.$, $30 \mathrm{mg} / \mathrm{l} ; \mathrm{KH}_{2} \mathrm{PO}_{4}, 15 \mathrm{mg} / \mathrm{l}$ ) for $190 \mathrm{~min}$ and no addition of chemical substances for $50 \mathrm{~min}$. Groundwater samples $(500 \mathrm{ml})$ were collected for microbiological analysis before the start of biostimulation treatment (September 24, 1998), and $10,24,31,40,45,52,60,66,73$ days after the start of treatment. The samples were transported to the laboratory on ice and used for DNA extraction within $24 \mathrm{~h}$.

\section{$16 S$ rDNA primer design}

Type I and type II methanotroph-specific primers were designed by aligning representative $16 \mathrm{~S}$ rDNA sequences of methanotrophs obtained from DDBJ, GenBank, and RDP with Clustal W (version 1.74). Selected regions unique to each group were tested against GenBank with BLAST (version 2.0.11) and FASTA (version 3.0t74) to check their specificity. The methanotroph-specific primers are listed in Table 1. Chromosomal DNA was extracted from Methylomonas sp. KSP III, Methylomonas sp. KSW III, Methylocystis sp. M, Methylosinus trichosporium OB3b, Aeromonas hydrophila ATCC 7966, E. coli K12 W3110, and Flavobacterium breve GIFU 3159, and used for PCR amplification with the methanotroph-specific primer sets to check the specificity.

\section{DNA extraction}

Baterial DNA from the groundwater sample obtained at sampling well S2 was extracted by the method of Teske et al. ${ }^{17)}$, modified as follows. The groundwater sample $(200 \mathrm{ml})$ was filtered with polycarbonate filters (Millipore; pore size $0.2 \mu \mathrm{m})$ to collect bacteria. The filter was added to $2 \mathrm{ml}$ of AE buffer $(20 \mathrm{mM}$ sodium acetate [pH 5.5],

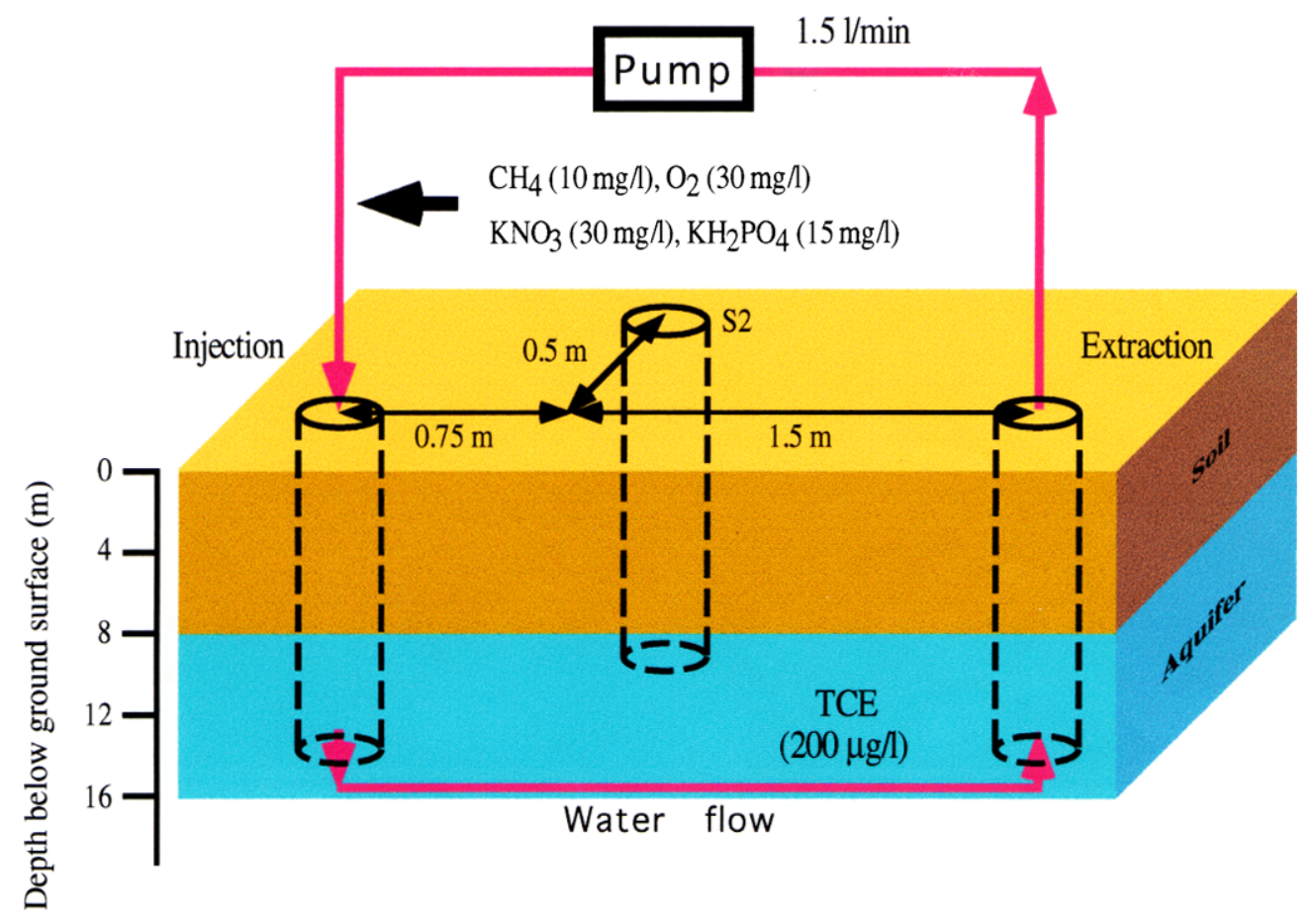

Fig. 1. Scheme of the location of sampling well S2, injection well, and extraction well at Kururi test site. 
Table 1. Methanotroph-specific primers.

\begin{tabular}{ccc}
\hline Name (sequence) & Target genera & E. coli position \\
\hline MI-f (5'-GGGTTGTAAAGCACTTTCAA-3') & Methylomonas & $423-442$ \\
MI-r (5'-CTGGATGTCAAGGGTAGG-3') & Methylobacter & Methylomicrobium \\
& Methylomonas & $984-1001$ \\
MII-f (5'-TTTCGCCAGGGACGATAAT-3') & Methylobacter & $437-455$ \\
MII-r (5'-GTCAAAAGCTGGTAAGGTTCTGC-3') & Methylomicrobium & Methylocystis \\
& Methylosinus & $973-995$ \\
\hline
\end{tabular}

$1 \mathrm{mM}$ EDTA) and frozen two times in liquid nitrogen and thawed at room temperature. The filter and buffer were added to $6 \mathrm{ml}$ of Tris-EDTA buffered phenol-chloroformisoamylalcohol $(25: 24: 1, \mathrm{pH} 8.0)$ and $60 \mu \mathrm{l}$ of $25 \%(\mathrm{w} / \mathrm{v})$ sodium dodecyl sulfate (SDS). After $5 \mathrm{~min}$ of incubation at $60^{\circ} \mathrm{C}$, the solution was cooled on ice for $3 \mathrm{~min}$ and then centrifuged for $5 \mathrm{~min}$ at $3,500 \mathrm{~g}$. The supernatant was transferred to a new tube and $250 \mu \mathrm{l}$ of $2 \mathrm{M}$ sodium acetate, $\mathrm{pH}$ 5.2, was added. Nucleic acids were precipitated with 2.5 volumes of $100 \%$ ethanol for $3 \mathrm{~h}$ at $-20^{\circ} \mathrm{C}$, and the precipitation was followed by $60 \mathrm{~min}$ of centrifugation at 3,500 g. The pellet was washed with $75 \%$ ethanol, dried for $10 \mathrm{~min}$ under a vacuum, and redissolved in $50 \mu \mathrm{l}$ of sterile distilled water.

\section{PCR amplification}

The DNA extracted from groundwater samples was amplified by PCR with the reagents supplied with AmpliTaq Gold $^{\mathrm{TM}}$ (Perkin-Elmer Applied Biosystem) at a magnesium ion concentration of $3 \mathrm{mM}$ and $20 \mathrm{pmol}$ of each primer in a $50 \mu \mathrm{l}$ reaction mixture. To amplify type I methanotrophic 16S rDNA, the primers MI-f-GC clamp and MI-r were used (Table 1). PCR was carried out under the following conditions; $9 \mathrm{~min}$ at $95^{\circ} \mathrm{C}$ for hot start, followed by 35 cycles of $94^{\circ} \mathrm{C}$ for $1 \mathrm{~min}, 51^{\circ} \mathrm{C}$ for $1 \mathrm{~min}$, and $72^{\circ} \mathrm{C}$ for $3 \mathrm{~min}$. The final extension step was at $72^{\circ} \mathrm{C}$ for $7 \mathrm{~min}$. To amplify type II methanotrophic $16 \mathrm{~S}$ rDNA, the primers MII-f-GC clamp and MII-r were used (Table 1). PCR was carried out under the following conditions; $9 \mathrm{~min}$ at $95^{\circ} \mathrm{C}$ for hot start, followed by 38 cycles of $94^{\circ} \mathrm{C}$ for $1 \mathrm{~min}, 53^{\circ} \mathrm{C}$ for $1 \mathrm{~min}$, and $72^{\circ} \mathrm{C}$ for $3 \mathrm{~min}$. The final extension step was at $72^{\circ} \mathrm{C}$ for 7 min. The presence and size of amplification products were determined by polyacrylamide gel electrophoresis and ethidium bromide staining.

\section{DGGE analysis}

PCR products $(30 \mu \mathrm{l})$ were loaded onto $6.5 \%(\mathrm{w} / \mathrm{v})$ polyacrylamide gel in 1X TAE (40 mM Tris, $20 \mathrm{mM}$ acetic acid, and $1 \mathrm{mM}$ EDTA at $\mathrm{pH} 8.0)$. The $6.5 \%(\mathrm{w} / \mathrm{v})$ polyacrylamide gel (acrylamide/bisacrylamide [37.5:1]) was made with denaturing gradients ranging from 45 to $65 \%$ : $100 \%$ denaturant contains $7 \mathrm{M}$ urea and $40 \%$ formamide. The electrophoresis was run at $55^{\circ} \mathrm{C}$, first for $10 \mathrm{~min}$ at $20 \mathrm{~V}$ and subsequently for $12 \mathrm{~h}$ at $100 \mathrm{~V}$. After electrophoresis, the gel was stained for $20 \mathrm{~min}$ with SYBR Gold nucleic acid gel stain (Molecular Probes) as specified by the manufacturer. The DGGE gel was scanned with a FluorImager (Molecular Dynamics) using $488 \mathrm{~nm}$ argon laser and digital images were obtained by Image QuaNT (ver. 4-2-J).

\section{Sequencing of DGGE fragments}

The selected DGGE bands were excised with a razor blade. The DNA was retrieved from the acrylamide block with a Centrilutor (Amicon) at $150 \mathrm{~V}$ for $3 \mathrm{~h}$. The DNA was re-amplified with the same primer set but no GCclamp. PCR products were purified with a Wizard DNA Clean-up system (Promega) and used for subsequent sequence analysis. The sequence analysis was performed on an ABI 310 automated DNA sequencer (Perkin-Elmer) with the dye-terminator cycle sequencing reaction according to the manufacturer's guidelines.

\section{Nucleotide sequence accession numbers}

The sequence data for the selected DGGE bands, i.e. band 1 and band 3 have been deposited in DDBJ, with accession no AB040500 and AB040501, respectively. 


\section{Results and Discussion}

Methanotroph-specific phylogenetic probes have been developed to detect novel methanotrophs in the natural environment ${ }^{18)}$. However, most only target one genus. Because of this high specificity, these probes are not suitable for the investigation of the diversity of methanotrophs by DGGE. Therefore, we designed 16S rDNA primers with a broader specificity for type I and type II methanotrophs (Table 1). The number of mismatches between the target region on 16S rRNA and primer is less than 2 in each case. To determine the specificity of the PCR primers, chromosomal DNAs from four methanotrophs and other nonmethanotrophs were used as a template in PCR. Figure 2 (A) shows that only type I methanotrophs, Methylomonas sp. KSP III and Methylomonas sp. KSW III, gave a PCR product of the expected size with the type I-specific primer set, MI-f-GC clamp and MI-r. Figure 2 (B) shows that only type II methanotrophs, Methylocystis sp. M and Methylosinus trichosporium OB3b, gave a PCR product of the expected size with the type II specific primer set, MII-f-GC clamp and MII-r. We could separate the bands originating from the four tested strains on the DGGE gel with two primer sets.

Understanding changes in the diversity of the target bacteria during bioremediation will help to make the technology more reliable. However, current knowledge on this subject is insufficient due to limitations associated with traditional culture-based approaches. In the present study, DGGE was used to provide an overview of the diversity of type I and type II methanotrophs during a biostimulation field experiment. Figure 3 shows the results of DGGE analyses with the type I (A) and with type II methanotroph-specific primer sets (B). The DGGE profiles yielded simple banding patterns. The type I methanotrophic community profile showed a single intense band (band 1) at day 10 . This band disappeared at day 24 , and faintly re-emerged after day 45 . Sequence analysis of this band indicated $99 \%$ similarity with Methylobacter psychrophilus, which is a type I methanotroph. There is no report that Methylobacter possesses soluble methane monooxygenase (sMMO), which has received special attention in the bioremediation of TCE because the enzyme contributes to degradation of TCE. A diffuse band (band 2) was observed throughout the biostimulation treatment. This band was excised from the gel, its DNA retrieved, reamplified with the same type I methanotroph-specific primer set, and analyzed using DGGE. The resulting profile did not show a single band. Therefore, this band may be considered an artifact of the mixed template reaction. The type II methanotrophic community profile showed a single band appearing at day 31 , becoming an intense band after day 40. Sequence analysis of this band indicated $99 \%$ similarity with Methylocystis parvus, which is a type II methanotroph and has $\mathrm{sMMO}^{12}$. These results suggest a shift in the methanotrophic community from type I, which has no sMMO, to type II, which has sMMO during the biostimulation treatment.

The amount of methane available has been reported to influence competition between the type I and type II methanotrophs ${ }^{19-21)}$. In growth, type II methanotrophs are
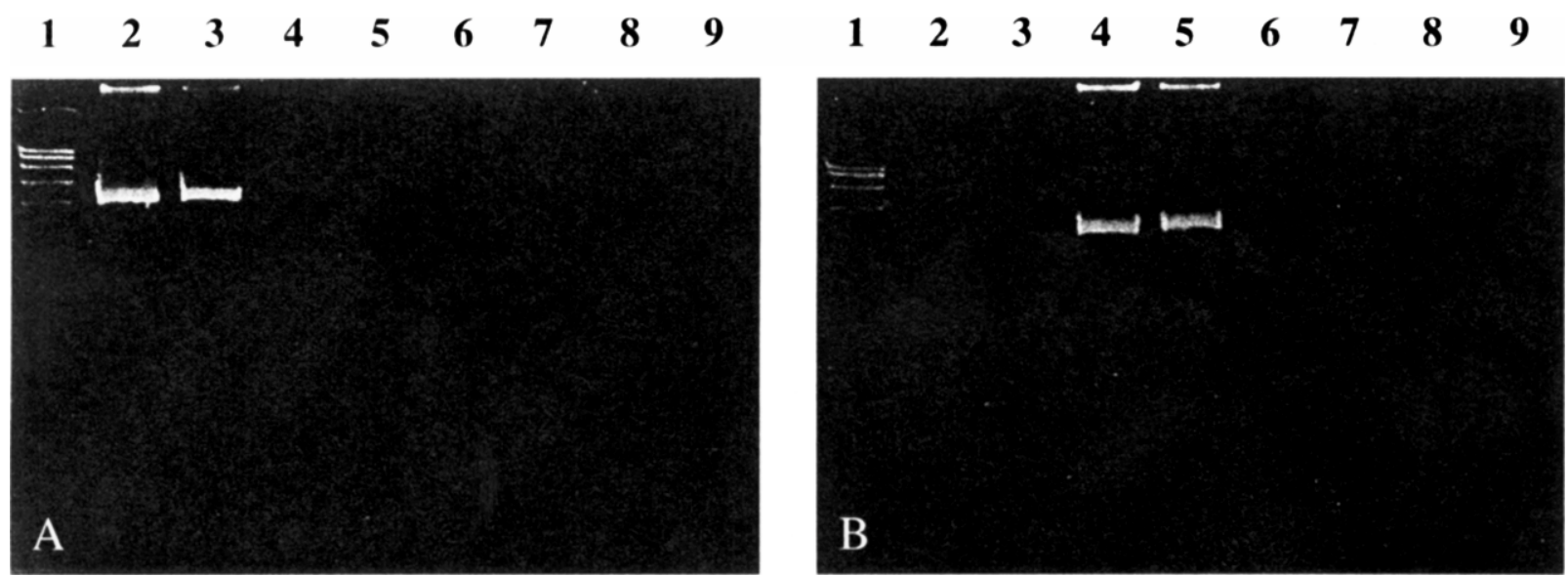

Fig. 2. PCR amplification of methanotroph DNA with type I methanotroph 16S rDNA-specific primers (A) and type II methanotroph 16S rDNA-specific primers (B). Lane 1 contained the pHY size marker. Lanes 2 to 9 contained PCR products obtained after amplification of methanotroph and non-methanotroph DNA template. Lane 9 contained no template DNA.Lane 2, Methylomonas sp. KSPIII; lane 3, Methylomonas sp. KSWIII; lane 4, Methylocystis sp. M; lane 5, Methylosinus trichosporium OB3b; lane 6, Aeromonas hydrophila; lane 7, Escherichia coli; lane 8, Fravobacterium breve. 

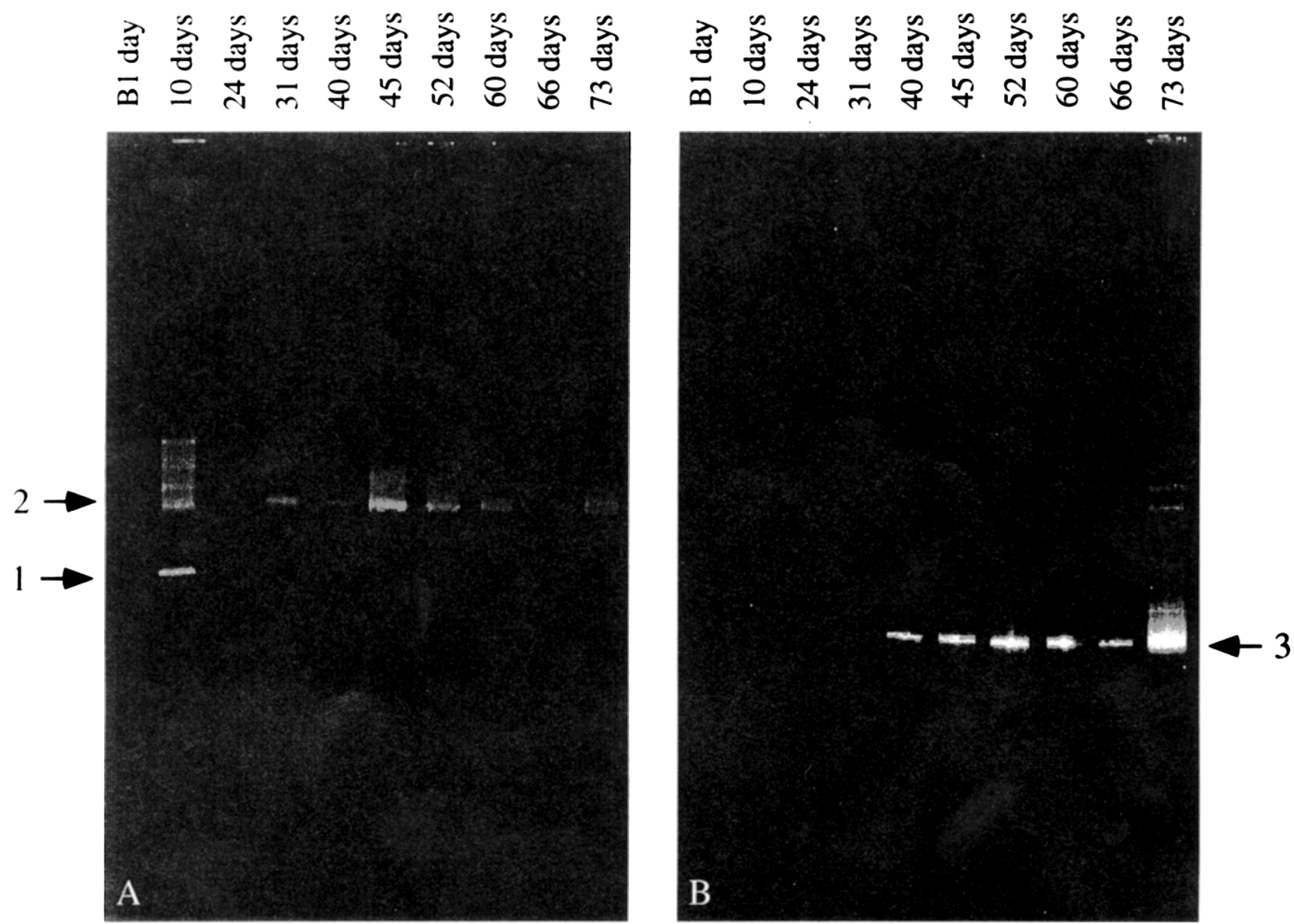

Fig. 3. DGGE analysis of PCR-amplified 16S rDNA fragments generated with primers specific for type I methanotrophs (A) and for type II methanotrophs (B) from sampling well S2 groundwater. The time course of the experiments is indicated above the lanes in days. B1 day, one day before the start of treatment.

more successful than type I methanotrophs at high methane concentrations, whereas type I methanotrophs are more successful at lower methane concentrations. The change of dominant methnotroph may be dependent on the concentrations of $\mathrm{CH}_{4}$ and $\mathrm{O}_{2}$ in groundwater. Continuous methane addition to in situ groundwater appears to favor the growth of type II methanotrophs. It is interesting, and perhaps fortunate, that the methane addition makes type II methanotrophs more competitive, because a number of type II methanotrophs possess sMMO, which is a key enzyme for TCE degradation and has received special attention in the bioremediation of TCE. There seemed to be a correlation between the presence of the type II methanotroph and TCE removal at the experimental site. The removal of TCE stabilized after day $40^{16)}$, when a single intense band of type II methanotroph appeared.

The PCR-DGGE approach employed in this investigation is effective for monitoring changes in the methanotrophic bacterial community during in situ biostimulation. Combining the approach with quantitative molecular techniques like FISH $^{22}$, may yield a more detailed picture of the changes in the methanotrophic bacterial community during biostimulation.

\section{Acknowledgements}

This work was conducted as one of the research and development activities of the bioremediation project which is handled by Research Institute of Innovative Technology for the Earth (RITE), Japan, and funded by the Ministry of International Trade and Industry (MITI) through the New Energy and Industrial Technology Development Organization (NEDO). We thank Kimitsu City Hall in Chiba Pref. for their kind cooperation. 


\section{References}

1) Alvarez-Cohen, L., P.L. McCarty, E. Boulygina, R.S. Hanson, G.A. Brusseau and H.C. Tsien. 1992. Characterization of a methane-utilizing bacterium from a bacterial consortium that rapidly degrades trichloroethylene and chloroform. Appl. Environ. Microbiol. 58: 1886-1893.

2) Bowman, J.P., L. Jimenez, I. Rosario, T.C. Hazen and G.S. Sayler. 1993. Characterization of the methanotrophic bacterial community present in a trichloroethylene-contaminated subsurface groundwater site. Appl. Environ. Mirobiol. 59: 2380-2387.

3) Dispirito, A.A., J. Gulledge, A.K. Shiemke, J.C. Murrell, M.E. Lidstrom and C.L. Krema. 1992. Trichloroethylene oxidation by the membrane-associated methane monooxygenase in type I, type II, and type X methanotrophs. Biodegradation 2: 151-164.

4) Little, C.D., A.V. Palumbo, S.E. Herbes, M.E. Lidstrom, R.L. Tyndall and P.J. Gilmer. 1988. Trichloroethylene biodegradation by a methane-oxidixing bacterium. Appl. Environ. Microbiol. 54: 951-956.

5) Oldenhuis, R., J.Y. Oedzes, J.J. van der Waarde and D.B. Janssen. 1991. Kinetics of chlorinated hydrocarbon degradation by Methylosinus trichosporium OB3b and toxicity of trichloroethylene. Appl. Environ. Microbiol. 57: 7-14.

6) King, G.M. 1992. Ecological aspect of methane oxidation, a key determinant of global methane dynamics. Adv. Microb. Ecol. 12: 431-468.

7) Bowman, J.P., L.I. Sly, P.D. Nichols and A.C. Hayward. 1993. Revised taxonomy of the methanotrophs: description of Methylobacter gen. nov., emendation of Mehylococcus, validation of Mehylosinus and Mehylocystis species, and a proposal that the family Methylococcaceae includes only the group I methanotrophs. Int. J. Syst. Bacteriol. 43: 735-753.

8) Bowman, J.P., L.I. Sly and E. Stackebrandt. 1995. The phylogenetic position of the family Methylococcaceae. Int. J. Syst. Bacteriol. 45: $182-185$.

9) Hanson, R.S. and T.E. Hanson. 1996. Methanotrophic bacteria. Microbiol. Rev. 60: 439-471.

10) Holmes, A.J., N. J.P. Owens and J.C. Murrell. 1995. Detection of novel marine methanotrophs using phylogenetic and functional gene probes after methane enrichment. Microbiology 141: 19471955.

11) Dedysh, S.N., N.S. Panikov, W. Liesack, R. Grosskopf, J. Zhou and J.M. Tiedjie. 1998. Isolation of acidophilic methane-oxidiz- ing bacteria from northern peat wetlands. Science 282: 281-284.

12) Hanson, R.S. 1980. Ecology and diversity f methylotrophic bacteria. Adv. Appl. Microbiol. 26: 3-39.

13) McDonald, I.R., E.M. Kenna and J.C. Murrell. 1995. Detection of methanotrophic bacteria in environmental samples with the PCR. Appl. Environ. Microbiol. 61: 116-121.

14) Amann, R.I., W. Ludwig and K.-H. Schleifer. 1995. Phylogenetic identification and in situ detection of individual microbial cells without cultivation. Microbiol. Rev. 59: 143-169.

15) Hanada, S., T. Shigematsu, K. Shibuya, M. Eguchi, T. Hasegwa, F. Suda, Y. Kamagata, T. Kanagawa and R. Kurane. 1998. Phylogenetic analysis of trichloroethylene-degrading bacteria newly isolated from soil polluted with the contaminant. J. Ferment. Bioeng. 86: 539-544.

16) Iwamoto, T., K. Tani, K. Nakamura, Y. Suzuki, M. Kitagawa, M. Eguchi and M. Nasu. 2000. Monitoring impact of in-situ biostimulation treatment on groundwater bacterial community by DGGE. FEMS Microbiol. Ecol. 32: 129-141.

17) Teske, A., C. Wawer, G. Muyzer and N.B. Ramsing. 1996. Distribution of sulfate-reducing bacteria in a stratified fjord (Mariager Fjord, Denmark) as evaluated by most-probablenumber counts and denaturing gradient gel electrophoresis of PCR-amplified ribosomal DNA fragments. Appl. Environ. Microbiol. 62: 1405-1415.

18) Holmes, A.J., N.J.P. Owens and J. C. Murrell. 1995. Detection of novel marine methanotrophs using phylogenetic and functional gene probes after methane enrichment. Microbiology. 141: 19471955.

19) Graham, D.W., J.A. Chaudhary, R.S. Hanson and R.G. Arnold. 1993. Factors affecting competition between type I and type II methanotrophs in continuous-flow reactors. Microb. Ecol. 25: 117.

20) Amaral, J.A. and R. Knowles. 1995. Growth of methanotrophs in oxygen and methane counter gradients. FEMS Microbiol. Lett. 126: $215-220$.

21) Amaral, J.A., C. Archambault, S.R. Richards, and R. Knowles. 1995. Denitrification associated with group I and II methanotrophs in a gradient enrichment system. FEMS Microbiol. Ecol. 18: $289-298$.

22) Amann, R.I., B.J. Binder, R.J. Olson, S.W. Chisholm, R. Devereux and D.A. Stahl. 1990. Combination of 16S rRNAtargeted ologonucleotide probes with flow cytometry for analyzing mixed microbial populations. Appl. Environ. Microbiol. 56: $1919-1925$. 